\title{
Remarks on Impure Quotation
}

\author{
MARIO GÓMEZ-TORRENTE \\ ICREA \& Univ. de Barcelona, Dep. de Lógica, Baldiri Reixac, s/n, 08028 Barcelona, Spain \\ Instituto de Investigaciones Filosóficas, UNAM, México DF 04510, Mexico \\ mariogt@servidor.unam.mx
}

\begin{abstract}
Quotation marks are ambiguous, although the conventional rules that govern their different uses are similar in that they contain quantifications over quotable expressions. Pure uses are governed by a simple rule: by enclosing any expression within quotation marks one gets a singular term, the quotation, that stands for the enclosed expression. Impure uses are far less simple. In a series of uses the quotation marks conventionally indicate that (part of) the enclosed expression is a contextually appropriate version of expressions uttered by some relevant agent. When the quotation marks have this meaning, it is tempting to think of them as contributing that indication to the truth-conditional content of the utterance. I adopt a cautious attitude towards this hypothesis, for the evidence in its favor is inconclusive. In other uses the quotation marks conventionally indicate that the enclosed expression should be used not "plainly" but in some broadly speaking "distanced" way, or that it is being so used by the utterer, and typically context makes clear the exact nature of the "distance" at stake. In these cases the quotation marks do not even appear to contribute that indication to the truth-conditional content of the utterance.
\end{abstract}

I

Quotation marks are used for a variety of purposes. One that is especially significant is the purpose of referring to expressions. In cases where the role of quotation marks is just to help in this purpose we can speak of purely referential quotation, or simply pure quotation. In typical utterances of the following sentence, the quotation it contains will be used with a purely referential purpose:

"Socrates" has eight letters.

In earlier work (Gómez-Torrente (2001)) I have made two main claims about pure quotation. The first is that it can be understood as governed by a simple semantic principle, apparently first identified by Tarski (1933): by enclosing any expression within quotation 
marks one gets a singular term - a quotation — that stands for (refers to, denotes) the enclosed expression. ${ }^{1}$ The second is that a number of standard accounts of pure quotation that deny this principle violate independently entrenched disquotationalist intuitions. Thus, for example, on Davidson's (1979) view it is the quotation marks that constitute by themselves a singular term (abbreviating a description containing a demonstrative), which stands for the quoted expression. Given this view, disquotational sentences such as

(D1) “ “Socrates' ” stands for 'Socrates',

(D2) “ “ "Socrates' " " stands for " "Socrates' ", “ ، “ "Socrates' ", ” stands for “ “ "Socrates" ", ”,

etc. come out false - but they of course come out true given the simple principle above. my earlier paper I also reject popular but uncharitable attributions to Tarski of the manifestly absurd view that pure quotations are like proper names in all significant respects; the popularity of these attributions, which apparently originate with Davidson (1979), is especially pernicious because it has led many writers in this area to confuse the simple semantic mechanism just mentioned with the absurd "proper name theory".)

Let me speak of impure quotation in those cases where the purpose of using quotation marks is other than purely referential. Impure quotation covers a motley of uses of quotation marks. The following sentences containing quotations will typically be used with impure purposes, and from now on we will focus on their impure uses (think of (6) as written, for example, in a biography of Ford):

\section{I find Quine's “Two Dogmas of Empiricism” difficult.} 1,517 lives were lost despite the efforts of the "Titanic" crew. Ford said "Thinking is the hardest work there is", and that's right. 
Ford said that thinking is "the hardest work" there is.

Thinking is "the hardest work" there is.

John Lennon was expelled and sent to art school, "so I can fail there as well” (Guardian Weekly, November 2-8, 2000, p. 13).

Jones leads the way and Smith will "precede".

Peters made five hundred "smackers".

Smith's "music" records are on the shelf.

It's unclear that all impure and pure uses share a common conventional meaning, and it's also unclear that all the different impure uses share a common conventional meaning. Most uses of quotation marks do have some things in common, however, regardless of how significant semantically these commonalities may be. Let me call $\mathrm{S}^{-}$the result of omitting the quotation marks from a sentence S. Typically, if an utterance of a sentence S containing a quotation is appropriate in a certain context, then the sentence $\mathrm{S}^{-}$is also appropriate in that context, only less informative or more susceptible of undesired interpretations. ${ }_{\text {One }}$ basic common feature of most uses of quotation marks, shared by most uses of other punctuation marks, is that they respond, in part, to the purpose of adding in an economic way some information not conveyed by the simpler sentence without the quotation marks, or to the purpose of eliminating in an economic way some possible undesired interpretations of that simpler sentence.

$\left(1^{-}\right)$is perfectly appropriate in typical contexts where (1) is appropriate, but (1) economically prevents interpreting the utterer of $\left(1^{-}\right)$as trying to convey the claim that a certain person owns eight letters (for example); (2) economically prevents an interpretation of $\left(2^{-}\right)$on which it says that I find two dogmatic empiricist pronouncements of Quine's, as opposed to his famous paper, difficult; (3) economically prevents an interpretation of ( $\left.3^{-}\right)$ 
on which the crew is being called titanic, ${ }_{(4)}$ economically prevents the interpretation of $\left(4^{-}\right)$on which Ford would be said to have said: "Thinking is the hardest work there is, and that's right", and economically adds the information that the expression he uttered was "Thinking is the hardest work there is"; in the case of (5) and (6), the information is economically added to $\left(5^{\circ}\right)$ and $\left(6^{-}\right)$that Ford uttered "the hardest work"; $(7)$ economically prevents the interpretation of $\left(7^{-}\right)$on which the utterer would be saying that she can fail in art school given that Lennon was expelled and sent there (and presumably failed there), and economically adds the information that the expression Lennon uttered was "so I can fail there as well"; (8) economically adds to $\left(8^{-}\right)$the information that its utterer, who may or may not be being ironic, wants to distance himself from a certain malapropism, that has perhaps been just used by someone else; typically, (9) economically adds to $\left(9^{-}\right)$the information that its utterer wants to distance himself from a certain informal usage; typically, (10) economically adds to $\left(10^{-}\right)$the information that its utterer is being ironic.

The very simple typographical structure of quotations is especially suited to the purposes of economically adding information to sentences and of economically preventing undesired interpretations of them. By enclosing an expression within quotation marks one easily creates a new expression with a more informative role than the quoted expression, or with a role that is more explicitly one among the typical roles of the enclosed expression. But these roles of quotation marks are varied, and nothing in principle suggests that they must fulfill them in just one semantically unified way. With inspiration from Herbert Clark, François Récanati has claimed that quotation marks quite generally "conventionally indicate the fact that the speaker is demonstrating the enclosed words" ((2001), 680), where "demonstrating" does not have its typical meaning in the linguistics and philosophy literature, but means "illustrating" (the enclosed word's type) by exemplification (the 
example being the enclosed token) (see Récanati (2001), 640). sense of this vague claim so that it can seem true of all uses of quotation but not of any other use of expressions. In what sense does one "illustrate" a word type when one utters (3) or (10) but not when one makes any other use of language? Récanati says that with quotational "demonstrating" one intends "the addressee to pay conscious attention to the words one utters" ((2001), 639), but it's unclear both in what sense that alleged intention really exists when I utter (3) or (10), and in what sense it is ever fulfilled, for surely I don't pay any conscious attention to the word "titanic" when I'm presented with (3) or to the word "music" when I'm presented with (10). No conscious thought about words crosses the mind of the typical addressee of (3) or (10) (as opposed, perhaps, to the typical addressee of (1) or of the preceding sentence).

Unifying intuitions like Récanati's can be explained more simply than by postulating an ad hoc conventional meaning shared by all uses of quotation marks. What appears to happen is that all the different conventional roles that the quotation marks have share a feature in common, a feature naturally derived from their character of simple typographical complements to preexisting expressions. Each one of the general implicit rules that characterize the different conventional roles of the quotation marks always contains quantification over expressions different from the expression the rule is about (the quotation marks), and in fact over the expressions that can appear between quotation marks. Thus, for example, the simple semantic principle governing pure quotation says that "by enclosing any expression within quotation marks one gets a quotation that stands for the enclosed expression". (The tentative rules to be given below for making explicit the conventional indications of the quotation marks in their other meanings are similar, in using analogous quantifications.) In this the rules for quotation marks are different from the rules 
that presumably characterize the meanings of common expressions (e.g., " 'Aristotle' refers to Aristotle", " 'Dog' applies to dogs"). But the rules for the different uses of quotation marks are no different in this respect from the rules that arguably govern (uses of) other expressions, such as prefixes, infixes and suffixes; for example, presumably the rule governing one use of "un" goes something like this: "by prefixing 'un' to any word (of certain specific kinds) one gets an expression that means the opposite of the word to which 'un' is prefixed". Of course with affixes one does not invariably refer to, or "illustrate", or make the addressee pay conscious attention to, or do anything of the sort with the stem word, and it would be odd to claim that in a sense all affixes have the same meaning just because they have that feature in common. Just the same, with the quotation marks one need not always be referring to, or "illustrating", or making the addressee pay conscious attention to, or doing anything of the sort with the enclosed expression.

Just as an affix can be ambiguous ("un”, for example, can indicate opposition, but also mere negation), quotation marks may do, and in my view do do, very different things in substantively different ways. I will say that these different roles of the quotation marks correspond to different meanings of them, for I think that different conventional rules are involved in each different role, and I see no problem with talking of different "meanings" provided substantively different conventional rules are involved in each case. What are these meanings? In cases like (1), as I said, the quotation marks help create new singular terms that as a matter of convention semantically refer to the enclosed expression. In cases like (2) and (3), they again help create new singular terms that as a matter of convention semantically refer to the articles and ships (and poems, movies, planes, etc.) that are also named by the enclosed expressions. The exact theoretical description of their functioning in cases relevantly similar to (4)-(10) is less clear. In what remains I will sketchily defend the 
following view, somewhat different from all the views that are familiar to me from the recent literature. In cases like (4)-(7) the quotation marks conventionally indicate that the enclosed expression (or part of $\mathrm{it}^{\mathrm{B}}$ ) is a contextually appropriate version of expressions uttered by some agent or agents who are contextually relevant; when the quotation marks have this meaning, it is tempting to think of them as contributing that indication to the truth-conditional content of the utterance, and in cases like (4) and (5) this is especially tempting. However, I will recommend adopting a cautious attitude towards this truthconditional hypothesis about (4)-(7), for the evidence supporting it that I know of is inconclusive. In cases like (8)-(10), the quotation marks have a different meaning; they conventionally indicate that the enclosed expression should be used not "plainly" but in some broadly speaking “distanced" way, or that it is being so used by the utterer, typically context makes clear the exact nature of the "distance" at stake; in these cases the quotation marks do not even appear to contribute an element to the truth-conditional content of the utterance.

\section{II}

Let me start with cases (4)-(7). I will contrast my view with the views of Récanati (2001), Herman Cappelen and Ernie Lepore (1997), and Stefano Predelli (2003). On Récanati’s view, utterances of (4), (5), (6) express the same propositions as utterances of $\left(4^{-}\right),\left(5^{-}\right),\left(6^{-}\right)$ respectively. ${ }^{10}$ With the quotation marks the utterer may indicate something else, and typically he will indicate that Ford uttered the quoted words. But this indication in no way forms part of the truth-conditional content of the utterances, and according to Récanati it can be cancelled by the utterer ((2001), p. 685, n. 32), so it is not even a conventional indication carried by the quotation marks. As for (7), Récanati again claims that it expresses 
the same proposition as a certain utterance of $\left(7^{-}\right)$, but in this case an utterance of $\left(7^{-}\right)$as considered with respect to a context different from the actual context of utterance, specifically with respect to a context where Lennon is the speaker; the quotation marks indicate in part that this "context-shift" has taken place at the level of the determination of the semantic content of the utterance. No indication that Lennon uttered the quoted words is part of the truth-conditional content of the utterance, or even a conventional indication carried by the marks.

Cappelen and Lepore, on the other hand, make indications of this sort not only conventional indications carried by the quotation marks, but also a part of the truthconditional content of the utterances. They give the following truth-conditional analyses of (4) and (5):

$\left(4_{\mathrm{CL}}\right) \quad \exists u(u$ is an utterance \& $\operatorname{Says}($ Ford, $u) \& \operatorname{Sametokens}(u$, these $) \&$ Right(these)). Thinking is the hardest work there is.

$\left(5_{\mathrm{CL}}\right) \quad \exists u(u$ is an utterance \& Says(Ford, $u) \& \operatorname{Samesays}(u$, that $) \&$ Sametokens $(u$, these) $)$. Thinking is the hardest work there is,

where the "these" in $\left(4_{\mathrm{CL}}\right)$ demonstrates the utterance of "Thinking is the hardest work there is", the "that" in $\left(5_{\mathrm{CL}}\right)$ demonstrates the utterance of "Thinking is the hardest work there is" and the "these" in $\left(5_{\mathrm{CL}}\right)$ demonstrates only the subutterance of "the hardest work". Here "samesaying" is roughly the relation in which two utterances stand when they express the same proposition, and "sametokening" is roughly the relation in which two tokens stand when they are tokens of the same contextually relevant type; Cappelen and Lepore take these relations as primitive because they wish to "avoid countenancing (quantification over) 
dubious metaphysical entities" ((1997), 441) such as propositions and expression types.

Cappelen and Lepore (1997) do not give an analysis of cases such as (6) and (7).

One main problem with Récanati's account is that it is not based on a satisfactory treatment of the issue of cancellability. He says, correctly in my view, that one can cancel the typical suggestion of, say, (5), that Ford uttered the expression "the hardest work":

On the most natural interpretation of the demonstration [(the quotation)], the displayed words are ascribed to the very person whose attitude or speech act is reported. [footnote 18:] This is only the most natural interpretation, however. One can easily imagine a context in which a sentence exactly like [(5)] would be used with something other than the ascribee's utterance as target for the demonstration $(2001,660)$.

But it's not clear how to imagine such a context merely from what Récanati says, if one does not agree with his "one-meaning" view of the quotation marks. He refers the reader to Récanati (2000), p. 214, for an example of how cancellation might go, but the type of example one finds there is substantively different from (5), and potentially confusing. It is instead like this one: The chairperson says that "Quine" has not finished writing his paper.

Here we are asked to imagine that someone called James mistakes someone called McPherson for Quine, that the chairperson does not but says that McPherson has not finished writing his paper, and that the utterer of (11) realizes James's mistake and chooses to make a "de re" report of what the chairperson says using James's mistaken way of referring to McPherson. Then the utterer can "cancel" any suggestion that the chairperson used the word "Quine" by saying something like "But the chairperson did not refer to McPherson as 'Quine'. I'm just distancing myself from James's way of referring to 
McPherson". Now, in this scenario (11) involves a use of quotation marks of the type we find in (8)-(10), and thus it is doubtful that it is exploitable in order to show that one can cancel the mentioned suggestion of (5). The use in (11) may be based on a meaning of the quotation marks altogether different from the meaning they have in the typical uses of (4)(7). Recall this case: I am close to the river bank and I utter (12), I'm going to take a bath close to the bank.

But just after that I say “I don't mean close to the river bank, but close to the financial institution ten blocks away". To be sure, this is no real "cancellation", but simply a further utterance that makes clear which meaning of "bank" was at stake. It is unclear that the "cancellation" of the mentioned suggestion of (11) does not sound appropriate because something like that is going on. Thus the example cannot convince someone who does not accept that all uses of the quotation marks have the same meaning.

But one seems to be able to cancel the relevant suggestion of (5) by adding, for example, “The expression 'the hardest work' was not actually uttered by Ford, who made his utterance in German, but is a good translation of that part of what Ford said", or by adding "The expression 'the hardest work' was not uttered by Ford, who uttered words synonymous with these; actually these words were only uttered by Shaw”. In these cases we are not "canceling" merely by making clear that we have a meaning of the quotation marks in mind that is different from what the audience might expect. But if this is the way we can cancel the indication of (5) that Ford uttered "the hardest work", then it's unclear that a certain more general indication, that may reasonably be taken to be part of the meaning of the quotation marks in this use, can be cancelled. This is the indication that the 
expression "the hardest work" is a contextually appropriate version of an expression uttered by some agent or agents who are contextually relevant. Think of what happens when one tries to cancel this indication straightforwardly:

(13) Ford said that thinking is "the hardest work" there is. But I don't mean to imply that the expression "the hardest work" is in any way a contextually appropriate version of an expression uttered by some agent or agents who are contextually relevant.

To me (13) sounds absurd, and I take this to suggest that, in uses of quotation marks relevantly similar to (4)-(7), the indication that (the non-elliptical, non-clarificatory, etc., parts of 1 the quoted expressions are a contextually appropriate version of expressions uttered by some agent or agents who are contextually relevant is part of the conventional meaning of the quotation marks. Typically the context will determine what counts as an appropriate version, as well as what agent or agents are contextually relevant. Thus, if the context has made it clear that what counts as an appropriate version is an exact version, and that the relevant agent is Ford, then a "canceling" utterance like (14),

(14) Ford said that thinking is "the hardest work" there is. But I don't mean to imply that the expression "the hardest work" was uttered by Ford,

will again sound contextually absurd. Or consider again Récanati's example (11). In a different scenario, the quotation marks might have there the meaning they have in (4)-(7), and it might be clear in context that they indicate that the word "Quine" was uttered by James (and not necessarily by the chairperson); in that context it will sound absurd to add to (11) "But I don't mean to imply that the word 'Quine' was uttered by James", or "But I 
don't mean to imply that the word 'Quine' is in any way a contextually appropriate version of an expression uttered by someone who is contextually relevant".

In my view, the indication that (the non-elliptical, non-clarificatory, etc. parts of) the quoted expressions are a contextually appropriate version of expressions uttered by some agent or agents who are contextually relevant is part of the conventional meaning of the quotation marks as used in (4)-(7). A further question is this: Is this indication part of the truth-conditional content of utterances of (4)-(7), or is it something else? The fact that it does not seem to be possible to cancel the indication in question does not show by itself that the answer must be positive, for the felt absurdity of (13) and (14) may be due to some conventional feature of this use of the quotation marks other than their contribution to truth-conditions. We need some other test if we want to answer the question.

One possible test might attempt to exploit the intuitively close relationships between the notion of what is said and the notion of truth-conditional content. A test from Kent Bach's recent work on the notion of conventional implicature intends to provide a criterion for whether an element of a sentence contributes to what is said with an utterance of that sentence, in terms of the notion of indirect quotation (IQ):

(IQ test) An element of a sentence contributes to what is said in an utterance of that sentence if there can be an accurate and complete indirect quotation of the utterance (in the same language) which includes that element, or a corresponding element, in the "that"-clause that specifies what is said (Bach (1999), 340). 
If we replace "what is said" with "truth-conditional content", we get a corresponding test for whether an element of a sentence contributes to the truth-conditional content of an utterance of that sentence:

(TIQ test) An element of a sentence contributes to the truth-conditional content of an utterance of that sentence if there can be an accurate and complete indirect quotation of the utterance (in the same language) which includes that element, or a corresponding element, in the "that"-clause that specifies what is said.

Applied to the cases that concern us, the TIQ test seems to yield the result that the quotation marks contribute to truth-conditional content. Take (5) again. We can report, without absurdity or infelicity, accurately and completely, Jones's utterance of it by means of (15): Jones said that Ford said that thinking is "the hardest work" there is.

Unfortunately, the (TIQ) test is too unreliable. A punctuation sign like a comma arguably does not contribute to truth-conditional content, but clearly we can report accurately and completely utterances containing commas by means of indirect quotations of those utterances, containing commas in their "that"-clauses. Thus, for example, we can report Smith's utterance of "Jones brought a table, a chair, and a computer" by means of Smith said that Jones brought a table, a chair, and a computer.

Bach argues for the equation between "contributing to what is said" (in the sense of "what passes the IQ test") and "contributing to truth-conditional content" in the cases that interest 
him (Bach (1999), p. 340, n. 18), but his idea seems just too crude. He rejects the claim that conventional implicatures can fail to contribute to the truth-conditional content of the utterances that implicate them, on the grounds that a conventional implicature has a truthvalue and that the sentential element that generates it (e.g., "but") passes the IQ test. But it's unclear that an element of a sentence that passes the IQ test cannot conventionally indicate something with truth-value that, in spite of this, does not contribute to the truthconditional content of the utterance. Presumably the use of a comma conventionally indicates something with truth-value (e.g., in cases such as (16), the proposition that the elements that flank it signify distinct items in an enumeration), but it's doubtful that this very proposition is part of the truth-conditional content of the utterance.

Stefano Predelli $(2003,21 \mathrm{ff})$ has used another test to check the hypothesis that quotation marks as used in (6) and (7) contribute an element to truth-conditional content, an hypothesis he favors $(2003,18)$. Predelli has noted that one can use the natural internal negation of sentences like those in order to reject the corresponding indication that the expressions uttered by the relevant agent are the quoted expressions. This test can be applied also to cases like (4) and (5). This application suggests prima facie that that indication is part of the truth-conditional content of the utterances. Consider the following negations, accompanied in all cases by a clarificatory reason for the preceding assertion (here and in what follows we may suppose that what counts as a contextually appropriate version is an exact version, and that the contextually relevant agent is the obvious one):

$\left(4_{N}\right) \quad$ Ford did not say "Thinking is the hardest work there is", he said "Thinking is the toughest work there is".

$\left(5_{\mathrm{N}}\right) \quad$ Ford did not say that thinking is "the hardest work" there is, he said that thinking is "the toughest work" there is. 
$\left(6_{\mathrm{N}}\right)$ Thinking is not "the hardest work" there is, it is "the toughest work" there is.

( $7 \mathrm{~N}) \quad J o h n$ Lennon was not expelled and sent to art school, "so I can fail there as well"; he was expelled and sent to art school, "so I can screw up there as well".

In all these cases one seems to be able to negate without absurdity or infelicity the conventional indication of the quotation marks by means of the straightforward internal negation of the utterance in which they appeared.

Again unfortunately, the test is unreliable, for internal negations of many sentences may, if used with appropriate emphases, indicate a rejection of some indication that is arguably not contributing to truth-conditional content. To my utterance of

This is... chicken!

someone may reply

This is not... chicken! It is chicken, but there is no reason for joy.

and by this means indicate that he rejects the indication, made by means of the exclamation mark, that one ought to be happy about the thing in question being chicken. However, this indication arguably does not contribute to the truth-conditional content of my original utterance.

The least unreliable test I can think of is a variation on the negation test. It consists in constructing dialogues of the sort exemplified in $\left(4_{D}\right)-\left(7_{D}\right)$ below and asking whether they strike one as intuitively appropriate exchanges. If they did then the hypothesis that the 
quotation marks in their relevant meaning contribute their conventional indication to truthconditional content would be vindicated. One can think of these as e-mail exchanges.

(4 $\quad$ D -Ford said "Thinking is the hardest work there is". -That's false, because he didn't utter the word "hardest".

(5 $) \quad-$ Ford said that thinking is "the hardest work" there is. -That's false, because he didn't utter the word "hardest".

(6 $\left.{ }_{\mathrm{D}}\right) \quad-$ Thinking is "the hardest work" there is. -That's false, because Ford didn't utter the word "hardest".

(7D) -John Lennon was expelled and sent to art school, "so I can fail there as well".

-That's false, because he didn't utter the word "fail".

I think that $\left(4_{D}\right)$ and $\left(5_{D}\right)$ sound like appropriate exchanges, but also that $\left(6_{D}\right)$ and $\left(7_{D}\right)$ sound odd. In the case of $\left(6_{\mathrm{D}}\right)$ the lack of a reference to Ford may make evaluation difficult. One needs to place oneself in the appropriate context (an e-mail exchange between Ford biographers, for example). (6) may be no different from a large number of sentences appearing in a typical text, which cannot be evaluated for truth and falsehood without taking into account many clues from the text. Still, to my eye $\left(7_{D}\right)$ seems odd in the same way as $\left(6_{\mathrm{D}}\right)$, despite the explicit reference to Lennon.

The oddness of $\left(6_{\mathrm{D}}\right)$ and $\left(7_{\mathrm{D}}\right)$ suggests adopting a cautious attitude towards the hypothesis we are examining. How about the impression that $\left(4_{D}\right)$ and $\left(5_{D}\right)$ sound appropriate? Récanati proposes to address intuitions of essentially this sort by means of his theory of the existence of "pragmatic enrichments" of what is said. According to him, in

(17) He took out his key and opened the door 
the suggestion that the door was opened with the key that was taken out "does not remain external to the intuitive truth-conditions of the utterance" $(2001,672)$, despite the fact that it can be cancelled, because

it takes some reflection to realize that that fact was not explicitly articulated in the sentence. From a psychological point of view, the pragmatic suggestion is incorporated into what is asserted: A single mental representation is constructed using both linguistic and contextual clues (...) In such cases I say that the truth-conditional content of the utterance is pragmatically enriched. [footnote 22:] (...) The extra element contextually provided (...) does not correspond to anything in the sentence itself, hence it does not constitute a component of the compositionally articulated content of the utterance, yet it is part of its intuitive truth-conditional content $(2001,672)$.

In the case of (5), Récanati holds that an indication such as the indication that the expression "the hardest work" was uttered by someone relevant in the context is only part of the pragmatically enriched content of the utterance, but not of its compositionally articulated content.

I have no intuitions about the alleged psychological facts that Récanati uses to ground his hypothesis, and if they exist I doubt that they are of relevance for semantics. But it is at any rate clear that Récanati's analogy is very imperfect, for the quotation marks are an explicit element of sentences containing them, so in this respect they are fundamentally different from the elements that are only implicit in the examples used by Récanati, such as (17). Thus the analogy does not convincingly show that the quotation marks do not contribute an element to the truth-conditional content of the utterance.

$\left(4_{D}\right)$ and $\left(5_{D}\right)$ are perfectly natural. But my view is that it is doubtful that this shows that the quotation marks in (4) and (5) contribute their conventional indication to truth conditions. Note that "say" is ambiguous. In some cases it is a propositional attitude verb and in others it is simply synonymous with "utter". Utterers and readers of (4) or (5) have 
difficulties disentangling these two different acceptations of "say", and may confusedly accept that the conjunction of two different propositions, such as those expressed by (4)(A) and (4)(B), and (5)(A) and (5)(B), is a part of the truth-conditional content of (4) and (5), respectively:

(4) (A) Ford said [attitudinally] thinking is the hardest work there is.

(B) Ford said [non-attitudinally] "thinking is the hardest work there is".

(5) (A) Ford said [attitudinally] that thinking is the hardest work there is.

(B) Ford said [non-attitudinally], in part, "the hardest work".

Note that the quotations in (4)(B) and (5)(B) are just pure quotations, which clearly contribute to truth-conditional content. If this is what typically happens, there is a reasonable explanation for the impression that $\left(4_{D}\right)$ and $\left(5_{D}\right)$ are appropriate. It is simply that it is hard to distinguish the two senses of "say". If this is correct, then a change in the attitudinal verb ought to introduce oddness in the corresponding dialogue, especially if the attitude in question is intuitively less related to the act of uttering. Consider the following dialogue (assuming again that the contextually relevant indication of the first utterance is that Ford uttered exactly "the hardest work"):

-Ford suspected that thinking is "the hardest work" there is. -That's false, because he didn't utter the word "hardest".

Here we have, I think, an oddness similar to that produced by $\left(6_{\mathrm{D}}\right)$ and $\left(7_{\mathrm{D}}\right)$.

Cappelen and Lepore's account of the truth conditions of (4) and (5) essentially involves treating these utterances as expressing the propositions expressed by (4)(B) and by the conjunction of (5)(A) and (5)(B), respectively. And it proceeds by analyzing (5)(A) as 
in Davidson's paratactic theory of indirect discourse (on which there is no distinctive attitudinal sense of "say"), and of course by treating the quotations in (4)(B) and (5)(B) as pure. The account is unattractive, and not just because of the reasons to think that the proposed conventional indication of the quotation marks in (4) and (5) is not part of their truth-conditional content. First, it is based on Davidson's controversial identification of the attitudinal "say" with the non-attitudinal "say". Second, even assuming that the proposed conventional indication of the quotation marks were a part of truth-conditional content, Cappelen and Lepore's account would probably be inadequate for reasons connected to reasons why Davidsonian accounts of indirect discourse are widely believed to misdescribe truth conditions. An example of a problem for Cappelen and Lepore is that $\left(5_{\mathrm{CL}}\right)$, on widely accepted views of demonstratives, can only be true provided a token of "the hardest work" exists. However, it seems clear that (5) could be true even if no token of "the hardest work" existed. Ford might have said his aphorism in a world w in which no English speakers ever existed, and even used a language that doesn't actually exist to do so. It might be proposed that in such a case it's enough that a token of "the hardest work" that doesn't exist in w stands in the "sametokening" relation to the token uttered by Ford in w. But since this latter token doesn't actually exist, the "sametokening" relation must become one involving “dubious metaphysical entities" (non-existents, in this case), and then one wonders why one needs all the complications of the Davidsonians in the first place.

Predelli (2003) has claimed that Bach's (1999) and Stephen Neale's (1999) proposals about how to explain some intuitive features of alleged devices of conventional implicature can be profitably applied to uses of quotation marks in examples such as (6) and (7), and presumably to the explanation of the feeling of oddness created by $\left(6_{\mathrm{D}}\right)$ and $\left(7_{\mathrm{D}}\right)$. On a standard Gricean view, the sentence 
semantically implies (18)(i) and (18)(ii) but merely conventionally implicates (18)(iii):

(i) She is poor

(ii) she is honest

(iii) there is a certain contrast between her being poor and her being honest.

(18)(i) and (18)(ii) contribute to the truth-conditional content of (18), while (18)(iii) does not. This squares well with the oddness speakers perceive in $\left(18_{\mathrm{D}}\right)$ :

(18 $\quad-$ She is poor but honest.

-That's false, because there is no contrast between her being poor and her being honest.

Suppose that I am convinced that (18)(iii) is false. If somebody asks me whether (18) is true, my belief that (18)(iii) is false will not prevent me from answering that (18) is in fact true if I believe that (18)(i) and (18)(ii) are true. But according to Bach, this intuition can be explained without postulating that the falsity of (18)(iii) is compatible with the truth of (18) and hence without postulating that (18)(iii) is not part of the truth condition of (18). The explanation Bach proposes is that (18) semantically expresses all of (18)(i), (18)(ii) and (18)(iii), but (18)(iii) is (for reasons he refuses to speculate about) "secondary", less prominent psychologically than (18)(i) or (18)(ii):

our intuitions about sentences like [(18)] tend to be insensitive to the falsity of the secondary proposition being expressed. The force of these intuitions is neutralized once we allow that sentences 
can express two (or more) propositions of different degrees of prominence, and their ranking in prominence depends not only on linguistic form but also on contextual factors (1999, 352-3).

On Predelli's view, the case of quotation marks as used in (6)-(7) is analogous. Sentence (6) semantically implies (6)(i) and (6)(ii) (or something similar):

(i) Thinking is the hardest work there is.

(ii) The expression "the hardest work" is an appropriate version of an expression uttered by someone contextually relevant.

Suppose I become convinced that (6)(ii) is false, perhaps because I think that only the expression "the toughest work" was uttered by Ford, that he is the only contextually relevant agent, and that the only words that count as an appropriate version of what he said are the exact words he uttered. If somebody asks me whether (6) is true, my belief that (6)(ii) is false will not prevent me from answering that (6) is in fact true if I believe that (6)(i) is true. But this intuition is allegedly explainable without postulating that the falsity of (6)(ii) is compatible with the truth of (6) and hence without postulating that (6)(ii) is not part of the truth condition of (6). (6) may semantically express both (6)(i) and (6)(ii), but (6)(ii) will allegedly be less prominent psychologically than (6)(i).

I think that Predelli deserves credit for pointing out that quotation marks as used in (6) and (7) share some relevant features with alleged generators of conventional implicatures, like "but". 12 However, I do not feel comfortable following him in adopting Bach's apparatus and conclusions about the contribution to truth conditions of those devices. I'm not persuaded by Bach, despite the strengths of his arguments. As I said, I find his IQ test unreliable as a detector of elements making a truth-conditional contribution. And this is, as far as I can see, his basic positive consideration in favor of the claim that words like "but" 
make a truth-conditional contribution. ${ }^{13}$ On the other hand, his explanation of the oddness of $\left(18_{\mathrm{D}}\right)$ is simply a theoretical alternative to the more natural explanation that (18)(iii) is not part of the truth conditions of (18). In any case, it seems premature to adopt a view like Bach's or Predelli's, either in the case of "but" or in the case of the quotation marks as used in (6) and (7), before more work is done in this area.

(6)(i) $\left(=\left(6^{-}\right)\right)$does seem to express at least a part, and probably the whole, of the truthconditional content of $(6)$. And $\left(4^{-}\right)(=(4)(A))$ and $\left(5^{-}\right)(=(5)(A))$ do seem to express at least a part, and probably the whole, of the truth-conditional content of (4) and (5), respectively. However, the corresponding part of the truth-conditional content of relevantly similar sentences S cannot always be explicated straightforwardly in terms of the truth-conditional content of $\mathrm{S}^{-} .(7)$ is a case in point. We saw how Récanati proposed to explicate the truthconditional content of (7), and specifically of the quoted words. It seems more natural, however, to view the truth-conditional contribution of the quoted part as obtained from $\left(7^{-}\right)$ by first replacing the indexicals in the quoted expression with indexicals suitable to the context of utterance of (7) ("I" with "he", "can" with "could", in this case), and then compute the truth conditions of the utterance with respect to its own context. (In the same way, one must replace indexicals with suitable indexicals when one reports an utterance containing them in indirect discourse.) Unlike Récanati's, this algorithm doesn't break with the standard idea of computing the semantic content of an utterance with respect to its context (but the two algorithms may yield the same outputs).

There are cases where some quoted elements do not make any sort of truth-conditional contribution, such as:

Thinking is "the hardest (...) work" there is. 

There is no "sincerer [truer] love" than the love of food.

In (19), it seems impossible to view the ellipsis points as making a contribution to truth conditions, and in (20) the same can be said of the attempted clarification in brackets, which is not due to the agent who is alluded to by the quotation marks in the context (Shaw, if the context is as one might expect), but to the utterer of (20). Assuming the conventional indications of the ellipsis points and the brackets to be the natural ones, these expressions flunk the "dialogic" test above, as $\left(19_{D}\right)$ and $\left(20_{D}\right)$ seem definitely odd:

$\left(19_{D}\right) \quad-$ Thinking is "the hardest $(\ldots)$ work" there is.

-That's false, because Ford did not utter anything between "hardest" and "work". 14

(20 D) -There is no "sincerer [truer] love" than the love of food. -That's false, because "sincerer" is not clarified by "truer".

Yet other cases where $\mathrm{S}^{-}$does not straightforwardly give the truth-conditional content of $\mathrm{S}$ are cases where neither $\mathrm{S}$ nor $\mathrm{S}^{-}$have a truth-conditional content, even when they can both be typically used to convey certain bona fide propositions. Consider:

I read that nazi philosopher, Heidelger.

He read "that nazi philosopher, Heidelger". He said that he read that nazi philosopher, Heidelger. He said that he read "that nazi philosopher, Heidelger".

Récanati (2001) and Cappelen and Lepore (1997) think that (21) and (23) don’t express a proposition, while (22) and (24) do. In my view, all lack a truth-evaluable content, though in the case of (22) and (24) the question whether they have such a content is easily 
confused with the question whether they convey the conventional truth-evaluable indication of the quotation marks. Besides this, of course, (21)-(24) can all be used to convey the obvious corresponding propositions about Heidegger, for it will typically be clear in context that this is the utterer's reference for "Heidelger".

III

Perhaps quotation marks as used in (4)-(7) make a contribution to truth conditions, but the evidence for this claim is inconclusive. In cases like (8)-(10) the temptation to see the quotation marks as making a truth-conditional contribution is smaller, and I'm almost convinced that the idea is wrong. Here the quotation marks conventionally indicate that the enclosed expression should at best be used in a "distanced" way, or that it is being so used by the utterer. But they do not even appear to contribute this indication to truth-conditional content. About this I differ again from Récanati (2001), who rejects even the moderate thesis that that indication is conventional, and from Predelli (2003), who handles cases like (8)-(10) in the same way as he handles cases like (6) and (7), treating the indication in question as truth-conditional. I will end by offering some very sketchy considerations in favor of my view.

My reasons for rejecting Récanati's view are essentially the same as in the case of (4)(7). Note that the following attempt at canceling the proposed indication of (10),

(25) Smith's "music" records are on the shelf. But I don't mean to imply that the word "music" is in any way being employed by me or should be employed in a "distanced" way, 
sounds absurd, and again I take this to suggest that, in uses of quotation marks relevantly similar to (8)-(10), the indication that the enclosed expression is being used by the utterer in a "distanced" way is part of the conventional meaning of the quotation marks. Of course, (25) could be made proper sense of, in some cases, by interpreting the utterer as having used the quotation marks in order to quote someone's utterance of the word "music", but on the most natural view such a case would be analogous to the case of (12) and its spurious "cancellation".

$\left(8^{-}\right)-\left(10^{-}\right)$seem to give the truth-conditional content of (8)-(10). ${ }^{5}$ My rejection of the hypothesis that their proposed additional indication makes a truth-conditional contribution receives support from the "dialogic" test. Consider:

$\left(8_{\mathrm{D}}\right) \quad-$ Jones leads the way and Smith will "precede". -That's false, because you are not distancing yourself from your use of "precede", nor should one do so.

$\left(9_{\mathrm{D}}\right) \quad-$ Peters made five hundred "smackers".

-That's false, because you are not distancing yourself from your use of "smackers", nor should one do so.

$\left(10_{\mathrm{D}}\right) \quad-$ Smith's "music" records are on the shelf.

-That's false, because you are not distancing yourself from your use of "music", nor should one do so (in talking of Smith's records).

The results sound in fact even odder than $\left(6_{D}\right)$ and $\left(7_{D}\right)$. Perhaps the greater oddness of $\left(8_{\mathrm{D}}\right)-\left(10_{\mathrm{D}}\right)$ is due to the fact that the proposed conventional indications of (8)-(10) have to do in part with evaluative attitudes and may not be straightforwardly declarative, while the proposed conventional indications of (4)-(7) were straightforwardly declarative. Maybe there is here a genuine difference between (4)-(7) and (8)-(10) that 
could in some way be exploited in a defense of the view that in the former cases the quotation marks contribute their conventional indication to the truth conditions of the utterances. But as I said earlier, I don't see in principle any reason why conventional straightforwardly truth-evaluable indications should eo ipso make a truth-conditional contribution to utterances.

The negation test may be more helpful in the case of (8)-(10) than before. Consider:

$\left(8_{\mathrm{N}}\right) \quad$ Smith won't "precede"; you are not distancing yourself from your use of "precede", nor should one do so.

$\left(9_{\mathrm{N}}\right) \quad$ Peters did not make five hundred "smackers"; you are not distancing yourself from your use of "smackers", nor should one do so.

$\left(10_{\mathrm{N}}\right) \quad$ Smith's "music" records are not on the shelf; you are not distancing yourself from your use of "music", nor should one do so.

Consideration of $\left(8_{\mathrm{N}}\right)-\left(10_{\mathrm{N}}\right)$ suggests that one does not seem to be able to negate without absurdity or infelicity the proposed conventional indication of the quotation marks. Perhaps making very special efforts of emphasis one could in some cases convey a rejection of the relevant indications by means of these negations, but this possibility seems considerably more strained here than in the case of (4)-(7). Again a possibly genuine difference between (4)-(7) and (8)-(10). But it's not obvious that the difference is genuine or that, if genuine, it ought to be attributed to the existence of a truth-conditional contribution of the quotation marks in (4)-(7). 16

The quotation marks as used in (8)-(10) seem to work very much like devices which would seem to have, less controversially, the properties of carrying a certain conventional indication and not contributing this indication to truth-conditional content. Consider the expressions "(!)", "(?)" and "to put it ironically" in these sentences: 
(26) Jones still uses a typewriter (!).

(27) He says that smoking is good (?) for him.

(28) Smith's music records, to put it ironically, are on the shelf.

Assuming the conventional indications to be the natural ones, one gets dialogues that sound odd again:

(26) $\quad-$ Jones still uses a typewriter (!).

-That's false, because you are not surprised nor should one be surprised.

(27 $\mathrm{D}$ ) -He says that smoking is good (?) for him.

-That's false, because you are not in doubt nor should one be in doubt.

(28D) -Smith's music records, to put it ironically, are on the shelf.

-That's false, because you are not being ironic.

The case of quotation marks, as used in typical utterances of (8)-(10), is not substantively different, in my view, from the uses of "(!)", "(?)" and "to put it ironically" in (26)-(28). In fact, I take (28) to be more or less interchangeable with (10) in many contexts. In all these cases, the relevant expression seems to be the vehicle for the performance of a certain kind of linguistic act that is segregated from the act that fixes the truth-conditional content of the utterance. 17 
${ }^{*}$ I thank Philippe de Brabanter for his kind invitation to participate in this special issue, and for his extensive and searching comments on an earlier draft.

${ }^{1}$ This deliberately ambiguous formulation admits of refinement. For example, we may wish to propose more concretely that in a given context the referent of a pure quotation can be a certain contextually relevant expression type to which the enclosed token belongs, or even a certain contextually relevant token of an expression type to which the enclosed token belongs.

${ }^{2}$ Other theories to which this criticism applies include the Davidsonian accounts of Bennett (1988), GarcíaCarpintero (1994) and Cappelen and Lepore (1997), and the Fregean accounts of Washington (1992) and Reimer (1996). That the disquotationalist intuitions are independently entrenched can be amply documented. Simchen (2003) denies that (D1)-(D3) respond in any way to speakers' intuitions, but it's unclear to me from this unelaborated claim that Simchen is not simply thinking of typical speakers, who would of course be baffled by (D1)-(D3) without judging them either true or false. Speakers with a modicum of reflective exposure to quotation marks and to the notion of reference will assent to (D1)-(D3). I can report, for example, that Davidson emphatically said to me that (D1)-(D3) were true, but refused to accept that his theory implied that they were false. García-Carpintero (forthcoming) also grants that (D1)(D3) are intuitively true, but denies that this is a problem for Davidsonians, on the grounds that the notion of standing for, or of reference, for which (D1)-(D3) are true is an intuitive or pretheoretical notion, while the Davidsonian theorist is concerned with a theoretical notion of reference that need not accommodate all the features of the intuitive notion. As I already advanced in $(2001,134)$, I have no objection to replies of this sort, except that they make the Davidsonian theory look unattractive as compared with the simpler Tarskian theory of the main text, which doesn't need to postulate a divorce between intuition and theory in this case.

${ }^{3}$ In saying this I do not mean to commit myself to the view that $\mathrm{S}^{-}$is grammatically correct if $\mathrm{S}$ is or to the view that $\mathrm{S}^{-}$is semantically impeccable if $\mathrm{S}$ is. In fact I reject these theses, for one can surely quote 
nonsense. I simply mean that $\mathrm{S}^{-}$will typically be usable for a communicative purpose if $\mathrm{S}$ is usable for that purpose, though $\mathrm{S}$ will make this purpose clearer.

${ }^{4}$ The standard presence of the capitals does not prevent the mentioned interpretations of $\left(2^{-}\right)$and $\left(3^{-}\right)$. For example, I may have singled out what I consider two dogmas of Quine's empiricist philosophy and labeled them “Quine's Two Dogmas of Empiricism”. This labeling technique using capitals is not infrequent in philosophy papers. In the case of (3"), I may use the capital " $T$ " in order to emphasize the magnitude of the crew's efforts. The use of capitals for emphasis is perfectly standard, though perhaps less usual nowadays than it used to be.

${ }^{5}$ This use of "demonstrating" is conspicuous in Clark's writings, from which Récanati borrows it (see Clark and Gerrig (1990)). I find Récanati’s borrowing somewhat confusing in a research context where "demonstrating" has been used (for better or worse) with a substantively different meaning (roughly, "referring in the way that demonstratives refer").

${ }^{6}$ Part of the intuition that guides Récanati is, of course, that pure quotations and perhaps the quotations in (4)(7) are in some sense pictographic. But I think there is no intuitive inclination to take the quotations in (3) or (10) as pictographic in any sense. Note that the pictographic character of pure quotations does not imply their semantics, but the other way around.

${ }^{7}$ Of course, in pointing this out I do not mean to commit myself to the absurd view that quotation marks and affixes are analogous in all significant respects. For example, pure quotation marks can enclose meaningless expressions, but affixes are not attached to meaningless expressions. Pure quotations are in some sense pictographic, while words formed by affixing aren't, etc.

${ }^{8}$ The reason for this parenthetical qualification will be made clear below.

${ }^{9}$ Note that the presumable existence of this conventional indication does not imply that the utterer of a typical utterance of (10) intends the addressee to pay conscious attention to the quoted word "music". With (10) the utterer will typically intend his addressee to realize that he thinks Smith's productions are not music at all, but will hardly ever intend his addressee to have a thought about the English word "music". In the same way, the presumably conventional indication of (3) that "Titanic" (and not just " 'Titanic" ") is the name of something need not cross the mind of either utterer or addressee. 
${ }^{10}$ Recall that we are focusing on impure uses. Thus, for example, the uses of (4) we are focusing on are not cases of direct quotation, but cases of indirect quotation where the conjunction 'that' has been omitted from the complement clause.

${ }^{11}$ This parenthetical qualification is necessary if we are to allow that ellipsis points (and other devices, like clarifications in brackets), can occur inside quotation marks but are not implied to have been uttered by the agent that is relevant in the context.

${ }^{12}$ Récanati ((2001), 662ff) also postulates that a conventional indication of the quotation marks in (4) and (5) (and by implication in all uses) is a conventional implicature, but he takes this implicature to be the proposition that the quoted words are being used "demonstratively" (in his sense of the word).

${ }^{13}$ In a footnote Bach also employs what is essentially the negation test above, noting that, with an appropriate emphasis, the negation "She is not poor BUT honest; there is no contrast between her being poor and her being honest" may be successfully used to reject the contrastive indication of "but" (see Bach (1999), p. 345, n. 24). But as pointed out above, the negation test is also unreliable as a detector of elements making a truth-conditional contribution.

${ }^{14}$ The following dialogues also seem odd:

-Ford said "Thinking is the hardest (...) work there is".

-That's false, because Ford did not utter anything between "hardest" and "work".

-Ford said that thinking is "the hardest (...) work" there is.

-That's false, because Ford did not utter anything between "hardest" and "work".

${ }^{15}$ Récanati $(2001,674 \mathrm{ff})$ denies this, at least in cases like (8). He claims that $\left(8^{-}\right)$is not intuitively "entailed" by (8), and hence cannot have the same truth-conditional content. He also proposes a theory according to which in these cases the enclosed word makes the truth-conditional contribution it makes in the malapropist's idiolect (that of "proceed" in the utterer's idiolect). But I doubt that the intuition Récanati mentions is transparently one about semantic entailment, and I see no need to postulate his idea of an "idiolect-shift". Of course with (8) its utterer will normally manage to convey to his audience the proposition that Smith will proceed after Jones leads the way, but he will manage to do so thanks to the 
typical, fully pragmatic mechanisms by which audiences distinguish utterer's meaning from semantic meaning. Récanati's intuition that $\left(8^{-}\right)$does not follow from (8) is presumably due to the fact that he is focusing on what follows from the proposition that will typically (though by no means always) be conveyed by (8). An intuition of the same sort appears even in cases where there are no quotation marks in sight. Compare the case of a normal utterance of "Jones leads the way and Smith will precede" by a malapropist. Does it follow from what he said that Smith will precede? If we realize that he's confused, we may be naturally inclined to say that it doesn't follow, in a perfectly natural sense of "follow".

${ }^{16}$ One important phenomenon about the relation between the use of quotation marks in (4)-(7) (the "quoting" use) and their use in (8)-(10) (the "distance" use) is that an utterer sometimes employs the quotation marks in order to express at the same time both her attitude of distance with respect to the quoted expression and the information that this expression was uttered by someone relevant in the context. This may be the typical case with utterances similar to (8), (22) and (24) above. Philippe de Brabanter (personal communication) wonders if this phenomenon may not suggest that the quotation marks do, after all, have the same meaning in, say, (5) and (10). I cannot see how the phenomenon in question supports a univocity view, though. If one accepts that the "distance" indication is part of the conventional meaning of the quotation marks in some uses, then, in order to establish the ambiguity view it is sufficient to point to cases where the conventional "quoting" indication exists but the conventional "distance" indication doesn't. One may reject the idea that the "distance" indication is part of the conventional meaning of the marks in any of their uses (as Récanati does), and propose (unlike Récanati) that a conventional indication common to all of (4)-(10) is that the quoted expression has been uttered by some relevant agent (possibly including "imaginary" agents such as those appealed to in Sperber and Wilson's (1981) "quotational" or "echoic" theory of irony). If I understand him correctly, this is De Brabanter's tentative position. This view seems to me to be refuted by the existence of sentences like (10), which can be used ironically in perfectly imaginable situations where the alleged indication that "music" has been uttered by someone else is intuitively cancelable — even if that someone is an "imaginary" utterer. As far as I can tell, Sperber and Wilson's "echoic" theory of irony does not postulate that "echoic" indications are part of the conventional meaning of any linguistic component of ironic utterances, and seem rather to emerge as a result of some fully pragmatic process. (For 
more against "echoic" views of "scare" quotes see Saka (2004), section 3.3.) From my point of view, simultaneously "distance" and "quoting" uses of quotation marks can be most profitably explained as examples of zeugma, as in "The farmers broke the fence and with it the property law".

${ }^{17}$ It's worth mentioning that Bach (1999) would seem agree that "to put it ironically" does not contribute to truth conditions, for on his view it would not even contribute to what is said (it clearly flunks the IQ test). That expression seems to fall under his category of "utterance modifiers", devices conventionally designed to perform a "second-order" speech act in Grice's sense. Unfortunately Bach does not seem to have considered the case of "scare" quotes in his published work. 


\section{References}

Bach, K. (1999), “The Myth of Conventional Implicature”, Linguistics and Philosophy, vol. 22, 327-366.

Bennett, J. (1988), “Quotation”, Noûs, vol. 22, 399-418.

Cappelen, H. and E. Lepore (1997), "Varieties of Quotation", Mind, vol. 106, 429-450.

Clark, H. and R. Gerrig (1990), "Quotations as Demonstrations”, Language, vol. 66, 764-805.

Davidson, D. (1979), “Quotation”, in Davidson, Inquiries into Truth and Interpretation, New York: Oxford University Press, 1984.

García-Carpintero, M. (1994), “Ostensive Signs: against the Identity Theory of Quotation”, Journal of Philosophy, vol. 91, 253-264.

García-Carpintero, M. (forthcoming), "The Deferred Ostension Theory of Quotation”, Noûs.

Gómez-Torrente, M. (2001), “Quotation Revisited”, Philosophical Studies, vol. 102, 123-153.

Neale, S. (1999), “Coloring and Composition”, in K. Murasugi and R. Stainton (eds.), Philosophy and Linguistics, Boulder: Westview.

Predelli, S. (2003), "Scare Quotes and their Relation to other Semantic Issues", Linguistics and Philosophy, vol. 26, 1-28.

Récanati, F. (2000), Oratio Obliqua, Oratio Recta, Cambridge (Mass.): MIT Press.

Récanati, F. (2001), “Open Quotation”, Mind, vol. 110, 637-687.

Reimer, M. (1996), “Quotation Marks: Demonstratives or Demonstrations?”, Analysis, vol. 56, 131-142.

Saka, P. (2004), “Quotational Constructions”, Belgian Journal of Linguistics, this issue.

Simchen, O. (2003), "Meaningfulness and Contingent Analyticity", Noûs, vol. 37, 278-302.

Sperber, D. and D. Wilson (1981), "Irony and the Use-Mention Distinction”, in P. Cole (ed.), Radical Pragmatics, New York: Academic Press.

Tarski, A. (1933), “The Concept of Truth in Formalized Languages”, in Tarski, Logic, Semantics, Metamathematics, second edition, Indianapolis: Hackett, 1983.

Washington, C. (1992), "The Identity Theory of Quotation", Journal of Philosophy, vol. 89, 582-605. 